\title{
Rancang Bangun Aplikasi Keamanan Data Menggunakan Metode AES Pada Smartphone
}

\author{
Amir Mahmud Hasibuan \\ STMIK Budi Darma, Jl. Sisingamangaraja No.338 Medan, Sumatera Utara, Indonesia \\ http : //www.stmik-budidarma.ac.id // Email : amirmahmudhasibuan@gmail.com
}

\begin{abstract}
Cryptography is one technique used to improve the security aspects of information. Cryptography is the study of science and art to maintain a message or data information so that the data is safe. Cryptography supports the needs of two aspects of information security, namely secrecy (protection of the confidentiality of information data) and authenticity (protection against counterfeiting and changing unwanted information).

Along with the development of computer technology, the world of information technology requires a stronger and safer cryptographic algorithm. Currently the Advanced Encryption Standard (AES) is used as the latest standard cryptographic algorithm. For this reason, it is necessary to prepare an application that can secure a data and maintain its confidentiality so that it is not known by unauthorized parties. One alternative that can be used in making a data security application is by applying the Advanced Encryption Standard (AES) algorithm. hence the design of a data security application on a smartphone by designing the application of encryption and description of text data using the AES method. This method does a round of 10 rounds to get the results of encryption and decryption in the text.
\end{abstract}

Keywords: Cryptography, AES, Smartphone.

\section{PENDAHULUAN}

Keamanan data yang bersifat pribadi sangatlah penting pada teknologi smartphone sekarang ini, dimana sering terjadi pencurian data, menyalahgunakan data oleh pihak yang tidak berwenang pada smartphone. Seiring meningkatnya pencurian data, pembajakan data, serta penyalahgunaan data tersebut mengakibatkan kerugian bagi pemiliki data informasi tersebut. Agar data teks dapat dijaga kerahasiannya maka dirancang sebuah aplikasi kriptografi untuk menyandikan pesan teks menggunakan metode $A E S^{[5]}$

Kriptografi pada awalnya dijabarkan sebagai ilmu yang mempelajari bagaimana menyembunyikan pesan. Namun pada pengertian modern kriptografi adalah ilmu yang bersandarkan pada teknik matematika yang berkaitan dengan keamanan informasi seperti kerahasiaan, keutuhan data dan otentifikasi entitas.

AES merupakan sistem penyandian blok yang bersifat non-feistel kerena AES menggunakan komponen yang selalu memiliki invers dengan panjang blok 128. Penyandian AES menggunakan proses yang berulang disebut dengan ronde. jumlah ronde yang digunakan oleh AES tergantung panjang kunci yang digunakan. Enkripsi pesan teks pada AES adalah transformasi terhadap state secara berulang dalam beberapa ronde. state menjadi keluaran ronde, $\mathrm{k}$ masukan untuk ronde untuk ronde $\mathrm{k}-\mathrm{k}+1$.

Masalah yang dibahas dalam skripsi ini yaitu:

1. Bagaimana Proses enkripsi dan dekripsi metode AES ?

2. Bagaimana menerapkan metodeAES dalam pengaman data?

3. Bagaimana merancangperangkat lunak yang dapat diaplikasikan dengan kriptografi algoritma AES pada smartphone?

Dalam penelitian ini yang menjadi batasan masalah adalah: Data yang digunakan dalam algoritma AES dalam bentuk teks dengan panjang maksimal 128 bit. Aplikasi yang dirancang dengan metode AES menggunakan model enkripsi simetris Block Cipher dan hanya berjalan pada smartphone yang memiliki sistem operasi android. Perancangan aplikasi yang dibangun menggunakan bahasa pemrograman java untuk smartphone samsung.

Adapun manfaat dari perancangan aplikasi ini yaitu: Pengguna dapat memanfaatkan media smartphone untuk penyandian data teks atau kode informasi ke dalam bentuk kriptografi. Dapat dijadikan alternatif dalam pengamanan data teks. Mencegah pencurian dan penyalahgunaan data teks pada smartphone agar tidak bisa dilihat oleh orang lain ${ }^{[1]}$.

\section{LANDASAN TEORI}




\subsection{Keamanan Data}

Keamanan data telah menjadi bagian dari pengembangan teknologi informasi mengingat bahwa berjuta-juta bit informasi telah dipertukarkan dalam jaringan komputer terutama di internet. Masalah keamanan data dapat diklasifikasi ke dalam beberapa dimensi.

\subsection{Kriptografi}

Kriptografi pada awalnya dijabarkan sebagai ilmu yang mempelajari bagaimana menyembunyikan pesan. Namun pada pengertian modern kriptografi adalah ilmu yang bersandarkan pada teknik matematika untuk berurusan dengan keamanan informasi seperti kerahasian, keutuhan data dan otentikasi entitas. Jadi pengertian kriptografi modern adalah tidak saja berurusan hanya dengan penyembunyian pesan namun lebih pada sekumpulan teknik yang menyediakan keamanan informasi.

\subsection{Advanced Encryption Standard (AES)}

Pada tahun 90 -an, setelah beberapa tahun standar penyandian simetris DES dianggap tidak lagi aman, lembaga standar amerika serikat NIST (National Institute Of standars and Technology) membuat sayembara untuk menggantikan DES dengan sebuah sistem penyandian yang disebut dengan Advanced Encryption Standars pada tanggal 12 September 1997. NIST memberikan spesifikasi AES, yaitu harus memiliki panjang kunci 128 bit, 192 bit dan 256 bit.

Setelah beberapa seleksi, NIST memilih sistem penyandian Rijndael yang dikembangkan oleh Joan Daemen dan Vincent Rijment sebagai sistem penyandian AES pada tahun 2000. Pemilihan Rijndael berdasarkan pada kriteria:

1. Keamanan Sistem penyandian harus tahan terhadap serangan analisis sandi selain serangan secara brute force.

2. Biaya Sistem penyandian harus memiliki biaya komputasi dan memori yang efesien sehinggan dapat diimplementasikan secara perangkat keras maupun perangkat lunak.

3. Karakteristik algoritma dan implementasi Sistem penyandian harus bersifat terbuka, fleksibel, dan sederhana.

Pada tahun 2001 akhirnya NIST mempublikasikan AES sebagai standar pemrosesan dokumen pada dokumen FIPSPUB 197.

\subsubsection{Deskripsi AES}

AES merupakan sistem penyandian blok yang bersifat non-Feistel karena AES menggunakan komponen yang selalu memiliki invers dengan panjang blok 128 bit. Kunci AES dapat memiliki panjang kunci bit 128, 192 dan 256 bit. Penyandian AES menggunakan proses yang berulang yang disebut dengan ronde. Jumlah ronde yang digunakan oleh AES tergantung dengan panjang kunci yang digunakan. Setiap ronde membutuhkan kunci ronde dan masukan dari ronde berikutnya. Kunci ronde dibangkitkan berdasarkan kunci yang diberikan (Rifki Sadikin, 2012).

Tabel 1 Hubungan antara jumlah ronde dan panjang kunci AES

\begin{tabular}{|l|l|}
\hline Panjang Kunci AES (bit) & Jumlah Ronde (Nr) \\
\hline 128 & 10 \\
192 & 12 \\
256 & 14 \\
\hline
\end{tabular}

Sumber: Rifki Sadikin, 2012, 152

\subsubsection{Struktur Enkripsi AES}

Proses di dalam AES merupakan transformasi terhadap state. Sebuah teks asli dalam blo (128 bit) terlebih dahulu diorganisir sebagai state. Enkripsi AES adalah transformasi terhadap state secara berulang dalam beberapa ronde. State yang menjadi keluaran ronde $\mathrm{k}$ menjadi masukan untuk ronde $k e-k+1^{[4]}$.

\subsubsection{Transformasi-transformasi AES}

Algoritma enkripsi AES menggunakan 4 jenis transformasi: substitusi yang disebut dengan SubBytes, permutasi yang dengan ShiftRows, pencampuran yang disebut MixColumns, dan penambahan kunci yang disebut dengan AddRoundKey. Pada bagian ini ke-4 transformasi ini akan dibahas.

\subsubsection{SubBytes}

AES menggunakan substitusi nonliniar pada ukuran byte yang dengan SubBytes. Setiap elemen pada state dari elemen ${ }^{S} 0,0$ sampai dengan ${ }_{3,3}$ dikenakan transformasi SubBytes. Ada 2 cara untuk mengkomputasi substitusi dengan SubBytes, yaitu dengan menggunakan substitusi atau dengan menggunakan komputasi pada $\mathrm{GF}\left(2^{8}\right)$.

\subsubsection{ShiftRows}

Selain dengan menggunakan substitusi untuk mengganti nilai pada elemen state, AES menggunakan permutasi pada state. Transformasi permutasi pada state disebut dengan transformasi ShiftRows. ShiftRows dilakukan dengan menjalankan operasi circular shift left sebanyak $i$ pada baris ke- $i$ pada state. 
Transformasi shiftRows merupakan jenis transformasi permutasi, yaitu pengubahan posisi elemen pada state tanpa mengubah nilainya. Transformasi ShiftRows terlihat sederhana jika dilihat melalui representasi state. Namun, karena state adalah representasi blok dengan orientasi per kolom menjadikan transformasi ShiftRows menjadi rumit jika dilihat dari sudut pandang blok.

\subsubsection{MixColumns}

Tujuan transformasi MixColumns adalah mencampur nilai kolom-kolom pada state pada satu elemen pada state keluaran. Untuk melakukan pencampuran itu, transformasi MixColumns2 menggunakan operasi perkalian matriks dengan operasi perkalian dan penjumlahan menggunakan operator pada $\mathrm{GF}\left(2^{8}\right)$ dengan irreducible polynomial $\left(x^{8}+x^{4}+x^{3}+x+1\right)$.

\subsubsection{AddRoundKey}

Transformasi keempat yang digunakan pada penyandian AES adalah transformasi AddRoundKey. Transformasi AddRoundKey mencampur sebuah state masukan dengan kunci ronde dengan operasi eksklusif OR $\left(\oplus^{\tilde{\pi}}\right.$ ). Setiap elemen pada state masukan yang merupakan sebuah byte dikenakan operasi ekslusif OR dengan byte pada posisi yang sama di kunci ronde (kunci ronde direpresentasikan sebagai state).

Transformasi AddRoundKey merupakan transformasi yang bersifat self invers, yaitu transformasi invers sama dengan transformasi aslinya asalkan menggunakan kunci ronde yang sama ${ }^{[4]}$.

\subsection{Struktur Dekripsi AES}

Algoritma dekripsi merupakan kebalikan algoritma enkripsi AES. algoritma dekripsi AES menggunakan transformasi invers semua transformasi dasar AES memiliki transformasi invers, yaitu: InvSubBytes, InvShiftRows dan InvMixColumns. AddRoundKey merupakan transformasi yang bersifat self-invers dengan syarat menggunakan kunci yang sama ${ }^{[4] .}$

\subsubsection{InvShiftRows}

InvShiftRows adalah transformasi byte kebalikan dari transformasi ShiftRows. pada transformasi InvShiftRows dilakukan pergeseran bit ke kanan sedangkan pada ShiftRows dilakukan pergesean bit ke kiri.

\subsubsection{InvSubBytes}

InvSubBytes juga merupakan transformasi bytes yang berkebalikan dengan transformasi
SubBytes. pada InvSubBytes tiap elemen pada state dipetakan dengan menggunakan tabel Invers S-Box.

\subsubsection{InvMixColumns}

Setiap kolom dalam state dikalikan dengan matriks perkalian dalam AES. perkalian dalam matriks dapat dilihat di bawah ini :

$\left[\begin{array}{c}s_{0, c} \\ s_{1, c} \\ s_{2, c} \\ s_{3, c}\end{array}\right]=\left[\begin{array}{cccc}0 E & 0 B & 0 D & 09 \\ 09 & 0 E & 0 B & 0 D \\ 0 D & 09 & 0 E & 0 B \\ 0 B & 0 D & 09 & 0 E\end{array}\right]\left[\begin{array}{l}s_{0, c} \\ s_{1, c} \\ s_{2, c} \\ s_{3, c}\end{array}\right]$

Hasil dari perkalian pada matrik adalah :

$s_{0, c}=\left(\{0 E\} \bullet s_{o, c}\right) \oplus\left(\{0 B\} \bullet s_{1, c}\right) \oplus\left(\{0 D\} \bullet s_{2, c}\right) \oplus\left(\{09\} \bullet s_{3, c}\right)$

$s_{1, c}^{\prime}=\left(\{09\} \bullet s_{o, c}\right) \oplus\left(\{0 E\} \bullet s_{1, c}\right) \oplus\left(\{0 B\} \bullet s_{2, c}\right) \oplus\left(\{0 D\} \bullet s_{3, c}\right)$

$s_{2, c}=\left(\left\{0 D \mid \bullet s_{o, c}\right) \oplus\left(\{09\} \bullet s_{1, c}\right) \oplus\left(\{0 E\} \bullet s_{2, c}\right) \oplus\left(\{0 B\} \bullet s_{3, c}\right)\right.$

$s_{3, c}=\left(\{0 B\} \bullet s_{o, c}\right) \oplus\left(\{0 D\} \bullet s_{1, c}\right) \oplus\left(\{09\} \bullet s_{2, c}\right) \oplus\left(\{0 E\} \bullet s_{3, c}\right)$

\section{PEMBAHASAN}

\subsection{Analisa}

Masalah keamanan merupakan salah satu aspek/terpenting dari sebuah informasi. Android merupakan sebuah sistem informasi untuk perangkat mobile berbasis linux yang mencakup sistem informasi, android menyediakan platform terbuka bagi para pengembang untuk menciptakan aplikasi sendiri. Advanced Encryption Standard (AES) adalah algoritma enkripsi blok cipher dengan variabel panjang blok dan panjang kunci. Panjang blok dan panjang kunci yang digunakan adalah 128 bit. Dalam pengamanan data teks menggunakan algoritma kriptografi yang berguna untuk menyandikan pesan agar tidak dapat dibaca. Salah satu algoritma kriptografi yang digunakan adalah Advanced Encryption Standart (AES). sistem yang dirancang menggunakan algoritma AES dalam pengamanan data teks.

\subsubsection{Enkripsi dan Dekripsi Algoritma AES}

Langkah - langkah Enkripsi algoritma AES adalah sebagai berikut:

1. Ekspansi Kunci, langkah-langkahnya adalah:

a. Kunci AES 128 bit diorganisir menjadi 4 word dan disalin ke word keluaran $(w)$ pada 4 elemen pertama ( $w[0]$, $w[1], w[2], w[3])$.

b. Untuk elemen keluaran selanjutnya $w[]$, dengan $i=\{4, \ldots, 43\}$ dihitung sebagai berikut:
1) Salin $w[i-1]$ pada word $t$
2) Jika $i \bmod 4=0$ ( $i$ habis dibagi 4$)$ maka lakukan $w[i]=f(t, i)^{\oplus} w[i-$ 
4] dengan fungsi $f(t, \quad i)=$ SubWord $(\operatorname{RotWord}(t)) \stackrel{\oplus}{\oplus=\mathrm{RC}}[\mathrm{i} / 4]$.

Fungsi RotWord adalah fungsi geser sirkular ke kiri 1 byte pada satu word. Bila masukan RotWord adalah $\left\{b_{0}, b_{1}, b_{2}\right.$, $\left.b_{3}\right\}$ maka keluarannya adalah $\left\{b_{1}, b_{2}, b_{3}\right.$, $\left.b_{0}\right\}$. Sedangkan fungsi SubWord menggunakan transformasi SubBytes untuk mensubstitusi tiap elemen pada word nilai byte baru. Sedangkan $\mathrm{RC}[\mathrm{i}]$ adalah konstan yang didefinisikan oleh tabel 1.

Konstan RCon dapat dicari dengan cara lain dengan tidak menggunakan tabel 3.1 tetapi menggunakan kalkulasi pada $\mathrm{GF}\left(2^{8}\right)$ dengan modulus polinomial $x^{8}+$ $x^{4}+x^{3}+x+1$.

\begin{tabular}{|c|cccccccccc|}
\hline $\mathrm{I}$ & 1 & 2 & 3 & 4 & 5 & 6 & 7 & 8 & 9 & 10 \\
\hline $\mathrm{RC}[/]$ & 01 & 02 & 04 & 08 & 10 & 20 & 40 & 80 & $1 \mathrm{~B}$ & $3 \mathrm{C}$ \\
\hline
\end{tabular}

$\operatorname{RCon}[]=x^{\prime}$

3) Jika $i \bmod 4 \neq 0$, lakukan $w[]=t$ $w[i-4]$

2. AddRoundKey: melakukan XOR antara state awal (plainteks) dengan cipher key. Tahap ini disebut juga initial round.

3. Putaran sebanyak $\mathrm{Nr}-1$ kali. Proses yang dilakukan pada setiap putaran adalah:

a. SubBytes: substitusi byte dengan menggunakan tabel substitusi (Sbox).

b. ShiftRows: pergeseran baris-baris array state secara wrapping.

c. MixColumns: mengacak data di masing-masing kolom array state.

d. AddRoundKey: melakukan XOR antara state sekarang round key.

4. Final round: proses untuk putaran terakhir:
a. SubBytes
b. ShiftRows
c. AddRoundKey
Langkah - langkah Dekripsi adalah sebagai berikut:

1. Mengekspansi kunci dan putaran kunci sama dengan yang digunakan dalam proses Enkripsi

2. Meng-XOR kan ciphertext dengan kunci putaran 10

3. Melakukan transformasi InvShiftRows

4. Melakukan transformasi InvSubBytes

5. Melakukan transformasi invers AddRoundKey, InvMixColums, InvShiftRows, InvSubBytes sebanyak 10 putaran

6. Meng-XOR kan hasil 10 putaran dengan kunci

Maka dapat dihasilkan plaintext.

\subsubsection{Proses Pengamanan Data}

Misalkan:

$$
\begin{aligned}
& \text { Plaintext: AMIRMAHMUDHASIBU } \\
& \text { Cipherkey: ANSTMIKBUDIDARMA }
\end{aligned}
$$

Tahapan pertama yang dilakukan adalah:

1. Ubah plaintext dan cipherkey ke dalam bentuk heksadesimaldengan melihat tabel ASCII (American Standard Code for Information Interchange) maka hasilnya adalah:

Plaintext: 41 4d 4952 4d 4148 4d 5544 484153494255

Cipherkey: 41 4e 5354 4d 49 4b 4255 4449444152 4d 41

Dengan 16 byte blok data dan kunci yang berukuran 128 bit. maka blok data 128 bit untuk ukuran state adalah $4 \times 4$

2. Transformasikan plaintext yang sudah dirubah ke hexadecimal dalam bentuk tabel $4 \times 4$ seperti di bawah ini:

\section{Tabel 2 plaintext ke hexadecimal}

\begin{tabular}{|c|c|c|c|}
\hline \multicolumn{4}{|c|}{ Plaintext } \\
\hline$W_{0}$ & $W_{1}$ & $W_{2}$ & $W_{3}$ \\
\hline 41 & $4 d$ & 55 & 53 \\
\hline $4 d$ & 41 & 44 & 49 \\
\hline 49 & 48 & 48 & 42 \\
\hline 52 & $4 d$ & 41 & 55 \\
\hline
\end{tabular}

Untuk mencari putaran kunci digunakan rumus sebagai berikut:

$$
W_{4}=W_{0} \oplus \text { SubWord }\left(\text { RotWord }\left(W_{3}\right) \oplus\right.
$$

$R \operatorname{Con}[1]$

$$
\text { Karena } W_{3}=534942 \text { 55, maka }
$$

RotWord (geser posisi 1 bit)

$$
=49425553
$$

SubWord $=49425553$ di rubah dengan melihat tabel $S$-Box, maka

\section{$=3 \mathrm{~b} 2 \mathrm{c}$ fc ed}

Untuk mendapatkan RoundKey kolom II sampai kolom IV tidak perlu di XOR kan dengan Rcon, Rcon hanya digunakan untuk mendapatkan byte kolom I tiap putaran.

Hasil nya adalah:

$414 d 4952 \stackrel{\bar{\oplus}}{\oplus^{a}} 3 b$ 2c fc ed $\stackrel{\bar{I}}{\oplus} 01=7 b 60$ b4 be

4d $41484 \mathrm{~d} \stackrel{\overline{\tilde{C}}}{\oplus} 7 \mathrm{~b} 60 \mathrm{~b} 4 \mathrm{be} \quad=3423 \mathrm{fe} \mathrm{f} 1$

$55444841 \oplus 3423 \mathrm{fe} f 1=6563$ b2 b4

$53494255 \stackrel{\tilde{\oplus}^{\circ}}{65} 63$ b2 b4 = 3e 2a f8 e1

Maka dapat lah putaran kunci algoritma AES

Tabel 3 RoundKey 
ISSN : 2548-6985

\begin{tabular}{|c|c|c|c|c|c|c|c|c|c|c|c|c|c|c|c|}
\hline \multicolumn{4}{|c|}{ Round 1} & \multicolumn{4}{|c|}{ Round 2} & \multicolumn{4}{|c|}{ Round 3} & \multicolumn{4}{|c|}{ Round 4} \\
\hline $7 \mathrm{~b}$ & 34 & 65 & $3 e$ & $5 b$ & $2 e$ & $\mathrm{f} 3$ & Df & $d 6$ & 14 & c5 & $\mathrm{Bc}$ & $3 c$ & a9 & 50 & $\mathrm{ad}$ \\
\hline 60 & 23 & 63 & $2 a$ & b1 & 07 & 63 & $8 c$ & $0 \mathrm{a}$ & $1 \mathrm{a}$ & a7 & $\mathrm{a} 4$ & 05 & $3 d$ & 93 & $\mathrm{fa}$ \\
\hline b4 & fe & b2 & f8 & 58 & 47 & $3 d$ & $\mathrm{~Eb}$ & 06 & 43 & 30 & $1 \mathrm{c}$ & $5 f$ & $\mathrm{Ob}$ & 11 & aa \\
\hline $\mathrm{Be}$ & $\mathrm{f} 1$ & b4 & e1 & 11 & 52 & $1 f$ & $\mathrm{Fd}$ & 74 & b8 & $\mathrm{ce}$ & 39 & f9 & $4 d$ & af & e3 \\
\hline
\end{tabular}

\begin{tabular}{|c|c|c|c|c|c|c|c|c|c|c|c|c|c|c|c|}
\hline \multicolumn{1}{|c|}{ Round 5 } & \multicolumn{4}{c|}{ Round 6 } & \multicolumn{4}{c|}{ Round 7 } & \multicolumn{4}{c|}{ Round 8 } \\
\hline 49 & $5 \mathrm{a}$ & $4 \mathrm{c}$ & 73 & $3 \mathrm{~b}$ & $\mathrm{c} 6$ & 73 & $1 \mathrm{~b}$ & 90 & 54 & 86 & 76 & $\mathrm{c1}$ & $3 \mathrm{f}$ & $0 \mathrm{a}$ & $4 \mathrm{~d}$ \\
\hline 54 & 43 & 49 & 75 & 83 & $0 \mathrm{~b}$ & 09 & 64 & 65 & 75 & dc & $0 \mathrm{~b}$ & 49 & $\mathrm{a} 7$ & 90 & 74 \\
\hline Ac & 48 & 41 & d9 & $2 \mathrm{f}$ & 92 & $9 \mathrm{~b}$ & $1 \mathrm{~b}$ & 73 & $7 \mathrm{f}$ & 30 & 40 & 35 & ea & fe & 28 \\
\hline 49 & 55 & $4 \mathrm{e}$ & 83 & 29 & 58 & 27 & 73 & 44 & $\mathrm{bc}$ & $\mathrm{ec}$ & 45 & 56 & $5 \mathrm{~d}$ & $\mathrm{e} 7$ & 34 \\
\hline
\end{tabular}

\begin{tabular}{|c|c|c|c|c|c|c|c|}
\hline \multicolumn{4}{|c|}{ Round 9 } & \multicolumn{4}{c|}{ Round 10 } \\
\hline 2f & Ba & fa & ef & 31 & 46 & $1 f$ & a4 \\
\hline 29 & 73 & $5 e$ & $7 d$ & 50 & ef & aa & b1 \\
\hline 43 & 04 & 41 & $0 c$ & b3 & c0 & $9 a$ & 05 \\
\hline 85 & $4 b$ & 81 & c6 & $7 c$ & 78 & e9 & 44 \\
\hline
\end{tabular}

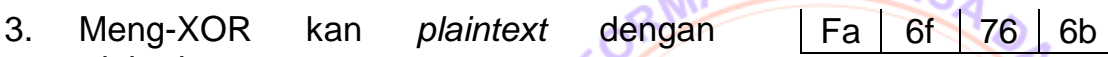

\section{cipherkey}

$41=01000001$ (plaintext)

$41=01000001$ (cipherkey)

Maka hasilnya $=00000000$ dalam bilangan hexadecimal $=00$

Hasil XOR

$\begin{array}{llll}00 & 00 & 00 & 12\end{array}$

$\begin{array}{llll}03 & 08 & 00 & 1 \mathrm{~b}\end{array}$

$1 \mathrm{a} \quad 03 \quad 01 \quad$ of

06 of $05 \quad 14$

4. Melakukan transformasi SubBytes

Hasil XOR S-Box

\begin{tabular}{|l|l|l|l|}
\multicolumn{3}{|c|}{00} \\
\hline 63 & 63 & 63 & $\mathrm{c} 9$ \\
\hline $7 \mathrm{~b}$ & 30 & 63 & $\mathrm{Af}$ \\
\hline $\mathrm{a} 2$ & $7 \mathrm{~b}$ & $7 \mathrm{c}$ & 76 \\
\hline $6 \mathrm{f}$ & 76 & $6 \mathrm{~b}$ & $\mathrm{Fa}$ \\
\hline
\end{tabular}

5. Melakukan transformasi ShiftRows

a. Baris pertama tetap atau tidak terjadi pergeseran

b. Baris ke dua bergeser 1 byte ke kanan

c. Baris ke tiga bergeser 2 byte ke kanan

d. Baris ke empat bergeser 3 byte ke kanan

\begin{tabular}{|c|c|c|c|}
\hline \multicolumn{4}{|c|}{ ShifRows } \\
\hline 63 & 63 & 63 & $\mathrm{c} 9$ \\
\hline 30 & 63 & af & $7 \mathrm{~b}$ \\
\hline $7 \mathrm{c}$ & 76 & $\mathrm{a} 2$ & $7 \mathrm{~b}$ \\
\hline
\end{tabular}

63
6. Transformasi MixColumns

Hasil dari ShiftRows di kalikan dengan matriks yang sudah ditentukan. Hasil perkalian tetap berada pada medan galois $\left(\mathrm{GF}\left(2^{8}\right)\right)$.

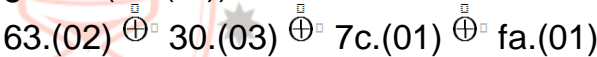

$01100011 .(00000010)^{\oplus}$

0110000.(00000011) $\oplus$

1111100.(00000001) ${ }^{\oplus}$

1111010.(00000001)

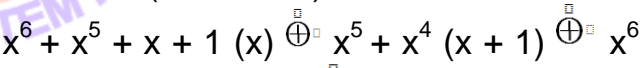

$+x^{5}+x^{4}+x^{3}+x^{2}(1){ }^{\oplus} x^{7}+x^{6}+x^{5}+x^{4}+$ $x^{3}+x(1)$

$=x^{4}+x=12$

\begin{tabular}{|c|c|c|c|}
\hline \multicolumn{4}{|c|}{ MixColumns } \\
\hline 12 & $\mathrm{~b} 3$ & 01 & $1 \mathrm{c}$ \\
\hline $7 \mathrm{~d}$ & 89 & 78 & $\mathrm{~d} 1$ \\
\hline Bd & Cc & Dc & 67 \\
\hline b8 & 22 & f9 & 30 \\
\hline
\end{tabular}

7. Melakukan transformasi AddRoundKey, SubBytes, ShiftRows, MixColumns sebanyak 10 putaran

\section{ALGORITMA DAN IMPLEMENTASI}

\subsection{Algoritma}

1. Enkripsi AES

Input:

$$
\begin{aligned}
& \mathrm{P}=\text { plaintext } \\
& \mathrm{K}=\text { Kunci }
\end{aligned}
$$


$\mathrm{P}, \mathrm{K}\{$ Teks asli 16 byte, Kunci AES (128 bit)\} Output:

$$
\mathrm{CT}=\text { Cipher Text }
$$

CT $\{$ Teks sandi 16 byte\}

Proses:

$$
\begin{aligned}
& \mathrm{Nr}=\text { Jumlah Putaran } \\
& w=\text { word }
\end{aligned}
$$

$(\mathrm{Nr}, w) \leftarrow$ EkspansiKunci $(\mathrm{K})\{\mathrm{Nr}$ : Jumlah Ronde, $\mathrm{w}$ : larik bytes kunci ronde $\}$

$$
\begin{aligned}
& \mathrm{CT}=\mathrm{P} \\
& \text { AddRoundKey (CT, } w[0 . .3]) \\
& \text { For } i=1 \rightarrow \mathrm{Nr} \text { do } \\
& \text { SubBytes (CT) } \\
& \text { ShiftRows (CT) } \\
& \text { if } i \neq N r \text { Then } \\
& \text { MixColumns }(\mathrm{CT}) \\
& \text { end if } \\
& \text { AddRoundKey (CT, } w\left[\left(i^{*} 4\right) . .\right. \\
& (i * 4)+3]) \\
& \text { end for }
\end{aligned}
$$

\section{Dekripsi AES}

Input:

$$
\begin{aligned}
& \mathrm{CT}=\text { Cipher Text } \\
& \mathrm{K}=\text { Kunci }
\end{aligned}
$$

CT, K \{Teks sandi 16 bytes, kunci AES (128 bit)\}

Output:

$$
\mathrm{P}=\text { Plaintext }
$$

$P\{$ Teks asli 16 bytes $\}$

Proses:

$$
\begin{aligned}
& \mathrm{Nr}=\text { Jumlah Putaran } \\
& w=\text { word }
\end{aligned}
$$

$(\mathrm{Nr}, w) \leftarrow$ EkspansiKunci $(\mathrm{K})$ \{Nr: Jumlah

Ronde, $\mathrm{w}$ : larik bytes kunci ronde\}

$$
\begin{aligned}
& \mathrm{P}=\mathrm{CT} \\
& \text { AddRoundKey }(\mathrm{P}, w[\mathrm{Nr} * 4 . \mathrm{Nr} * 4 \\
& \text { 3]) } \\
& \text { for } i=1 \rightarrow \mathrm{Nr} \text { do } \\
& \quad \text { InvSubBytes }(\mathrm{P}) \\
& \quad \text { InvShiftRows }(\mathrm{P}) \\
& \quad \text { AddRoundKey }(\mathrm{P}, w[(\mathrm{Nr}-i) \\
& \text { * } 4 . .((\mathrm{Nr}-i) * 4)+3]) \\
& \text { if } i \neq \mathrm{Nr} \text { then }
\end{aligned}
$$

InvMixColumns $(P)$

end if

end for

\subsection{Implementasi}

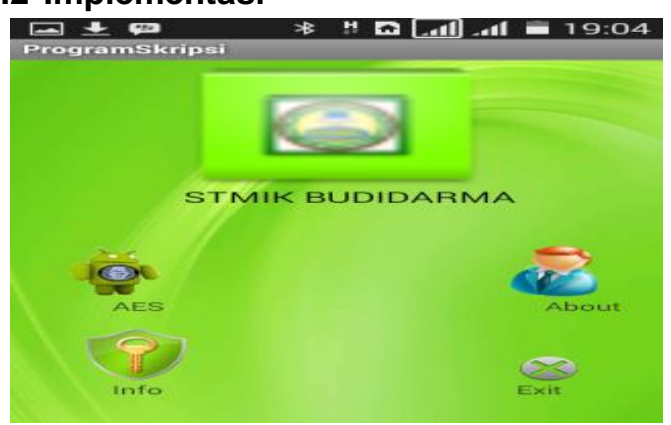

Gambar 1. Tampilan Utama

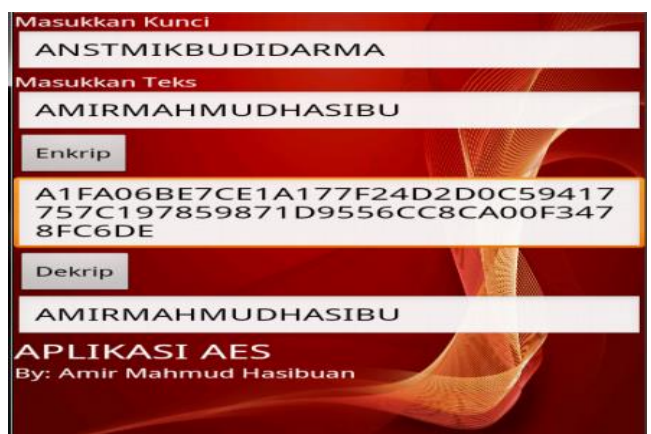

\section{Gambar 2 Tampilan AES}

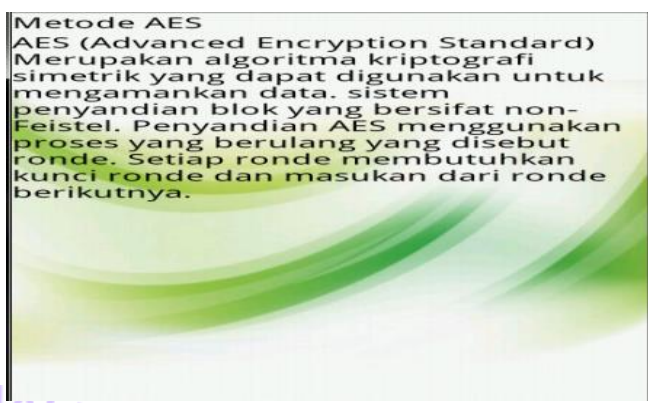

Gambar 3 Tampilan Info

\section{KESIMPULAN DAN SARAN}

\subsection{Kesimpulan}

Setelah merancang dan mengaplikasikan rancangan perangkat lunak keamanan data menggunakan metode AES maka dapat diambil kesimpulan bahwa:

1. perangkat lunak ini dapat mengkodekan data teks asli menjadi data teks campuran dan mengembalikan data teks tersebut seperti semula.

2. Sistem yang penulis rancang sudah dapat dijalankan pada Smartphone android.

3. Sistem yang penulis rancang masih bersifat data teks dan belum sampai pada pengiriman data teks.

\subsection{Saran}

Penulis menyadari bahwa aplikasi ini masih banyak kekurangan yang diharapkan diibutuhkan pengembangan lebih lanjut pada aplikasi. Adapun saran - saran dari penulis antara lain:

1. Untuk penelitian selanjutnya diharapkan data yang digunakan dalam algoritma AES dalam bentuk dokumen.

2. Aplikasi yang dirancang dapat menggunakan software yang lain seperti Visual Studio 2008 dan Macromedia Flash.

3. Pengembang dapat menambahkan tampilan halaman untuk login. 


\section{DAFTAR PUSTAKA}

1. Gata, Windu. (2013).Sukses Membangun Aplikasi Penjualan Dengan Java.Jakarta: Penerbit PT Elex Media Komputindo.

2. Jogiyanto. (2005). Analisis dan Desain Sistem Informasi. Yogyakarta: Penerbit Andi.

3. Nugroho, Adi. (2009). Rekayasa Perangkat Lunak Menggunakan UML dan JAVA. Yogyakarta: Penerbit Andi.

4. Sadikin, Rifki. (2012). Kriptografi Untuk Keamanan Jaringanan. Yogyakarta: Penerbit Andi.

5. Safaat H, Nazruddin. (2012) Pemrograman Aplikasi Mobile Smartphone Dan Tablet PC Berbasis Android. Bandung: Penerbit Informatika.

6. Simarmata, Janner. (2006). Pengenalan Teknologi Komputer dan Informasi. Yogyakarta: Penerbit Andi.

7. https://prezi.com/cqq4id3jtfqu/pengertia n-keamanan-komputer-dan-konsepkeamanan-jaringan.html

8. http://www.pintarkomputer.org/2015/03/ pengertian-android-menurut-paraahli.html 